\title{
Measuring Academic Life Satisfaction in Portuguese Students
}

\author{
Nogueira MJ* \\ University Lisbon School of Nursing, Portugal
}

*Corresponding author: Maria José Nogueira, PhD, MCs, RMHN, Prof. Adjunct at Atlântica School of Health, Barcarena, Portugal and Researcher at Research Group NursID: Innovation and Development in Nursing - CINTESIS- Center for Research in Health Technologies and Services FMUP, Porto, Portugal, Tel: +351915689883; E-mail: nogueira.mjc@gmail.com

\section{Abstract}

Student's academic life satisfaction (ALS) plays a relevant role as an indicator of student's academic success and wellbeing. However, literature shows a lack of instruments to measure ALS in Portugal. The aim of this paper is to present the concept elements and an instrument to measure Academic Life Satisfaction. Using a literature review, some relevant instruments come up to assess satisfaction with academic. Results indicate a lack of precise instruments to measure ALS in Portuguese's Students. Developaccurate tools to measure ALS, is important todesign programs to improve student's adjustment, academic success and wellbeing in the campus.
\end{abstract}

Keywords: Academic Life Satisfaction; Students Adjustment; Wellbeing; Measurements

Abbreviations: ALS: Academic Life Satisfaction; MMAU: Multidimensional Model of Adjustment of Young People to the University context; CSSQ: College Student Satisfaction Questionnaire; CSS: College Student Survey; HERI: Higher Education Research Institute; SSI: Student Satisfaction Inventory ${ }^{\mathrm{TM}}$; QAE: Questionnaire of Academic Experience; SAES: Satisfaction with Academic Experience Scale; ASSCS: Academic Satisfaction Scale for College Students.

\section{Introduction}

\section{Background}

Academic Life Satisfaction (ALS) is a complex multifactorial construct that includes the wide experiences of the students' life in the campus, as well the quality of students' adaptation to academic environment $[1,2]$. Academic adjustment is a major challenge for freshman that involves academic satisfaction, developmental aspects (personal, social and vocational), as well the academic environment and features of attended campus [3]. Currently, students' academic life satisfaction plays an important role as a key indicator of students' success and well-being $[2,4]$. In Portugal, in the last two decades a discussion on the construct and measurement of ALS remains [4,5]. Yet, there is a lack of instruments to measure ALS. So, this paper aims to present a review of Academic Life Satisfaction concept elements and some measurement instruments.

\section{Academic Life Satisfaction}

Academic life satisfaction (ALS) encompasses overall the experiences regarding to students' life in the academic environment and shows the quality of campus adaptation [4]. Literature review shows that three aspects must be considered to study and understand academic life satisfaction's multifactorial concept: (1) higher education transition is a vulnerability period with multiple and 


\section{Nursing \& Healthcare International Journal}

complex adjustment tasks and setting specificities; (2) adaptation tasks involve students' personal characteristics and may disturb their health, wellbeing and performance (3) students' ALS play a significant role in measuring institutional effectiveness $[4,6,7]$.

Recent research about student's transition to college established the positive relation between adaptability and life satisfaction [8]. The accomplishment of this transition depends on student's wellbeing, and how they face and surpass their challenges [6,9]. An important contributes to develop of ALS construct and measures came from the Multidimensional Model of Adjustment of Young People to the University context (MMAU) [10].

MMAU model advocates that student's transition and adjustment to the academic context do not occur dissociated from human's development or learning processes, on the contrary, it covers several dimensions: satisfaction with the pedagogical relations with teacher; physical environment and facilities of the campus; personal commitment to the course; extracurricular activities on campus; setting facilities to study; students skills and competences; self-perception of academic performance; and relationship with colleagues and teachers $[4,10]$.

In the scope of MMAU's model, the concept of ALS is influenced by student's personal characteristics, wellbeing and, by the subjective assessment and value of circumstantial academic experiences, all this combining with the cognitive and affective components $[10,11]$. So, ALS is a dynamic concept covering students' personal characteristics, relationships with teachers and colleagues, the quality of the curriculum and teaching, as well the conditions provided by the campus features and environment $[5,12]$.

\section{Adjustment and Wellbeing}

Student's adjustment and wellbeing involved several tasks grouped in four domains: (a) academic - (typically demanding) to continuous adaptations to new learning strategies, teaching and evaluation system; (b) personal to establish identity, expand self-awareness, develop selfesteem and a personal view of the world; (c) social - to develop progressively more mature interpersonal relationships (family, colleagues, teachers, colleagues of the opposite sex and authority figures); (d) vocational - to strength vocational identity and decision making, to explore and commit with professional goals. ALS's concept involves a multifaceted complexity process of experiences (personal, affective, cognitive aspects and institutional features and facilities) $[4,7,11]$. Hence, it is not easy to limit and to identify ALS's construct components, and to have agreement about how to measure it accurately $[4,12,13]$.

\section{ALS Measurements}

International research indicates some relevant instruments to measure ALS: the College Student Satisfaction Questionnaire (CSSQ) [1], with 70 items (5 points Likert scale) and 5 subscales (comprehension, social life, work conditions, recognition and educational quality); the College Student Survey (CSS) used by the Higher Education Research Institute(HERI), with items covering curriculum and teaching, services and support, student life, relationships with teachers and conditions and equipment(HERI) [14]; the Student Satisfaction Inventory ${ }^{\mathrm{TM}}(\mathrm{SSI})$ includes 45 core questions, three summary questions, and several standard demographic items. Additionally, institutions can add up to 10 campusspecific questions ( 7 points Likert scale).

In Portuguese speaking countries studies, some instruments with suitable psychometric properties came up to measure ALS: the Questionnaire of Academic Experience (QAE) [15-17], with 170 items and 17 subscales, later reduced to 60 items and 5 dimensions' structure (personnel; interpersonal; career; learning; institutional) and a Brazilian short version (QAE-r) [18], with 55 items and same 5 subscales structure showing appropriated; the Satisfaction with Academic Experience Scale(SAES) [19] has 35 items distributed by 3 factors (satisfaction with course; opportunities and development; satisfaction with the institution); and the Academic Satisfaction Scale for College Students (ASSCS) [12] with 35 items (4point Likert scale), distributed by 4 factors (pedagogic milieu; affectivity; campus milieu; self-esteem.

\section{Conclusion}

The present review shows that MMAU's model provides a conceptual framework to measure ALS's dimensions, involving student's core elements of adjustment and wellbeing. Also, indicates a lack of instruments to measure ALS in Portuguese's students. Despite the evidence of good psychometric properties of Portuguese instruments point out, authors are still discussing their effectiveness and suitability to measure student's ALS [4,11]. Additionally, some consider that most of this measures lack in strength in their underlying constructs, find them to extensive, meticulous or very specific. Also, differ in terms of variables or assign insufficient attention to dimensions like interpersonal relations, course or campus, covering particularly cognitive and psychosocial variables $[5,12]$. 


\section{Nursing \& Healthcare International Journal}

Overall, we can conclude that more research is needed to expand and develop suitable instruments to measure Portuguese student's ALS more accurately, assuming the inner aspects of adjustment process and setting conditions that involves students' life experience, as defended by MMAU model. Develop accurate tools to measure student's ALS is important to design suitableprograms to improve student's adjustment. This knowledge can improve success and add wellbeing to student's life in campus.

\section{References}

1. Betz EL, Klingensmith JE, Menne JW (1970) The measurement and analysis of college student satisfaction. Measurement and Evaluation in Counseling and Development 3: 110-118.

2. Ramos A, Barlem J, Lunardi V, Barlem E, Silveira R, et al. (2015) Satisfaction with academic experience among undergraduate nursing students. Texto \& Contexto - Enfermagem 24(1): 187-195.

3. Santos A, Suehiro A (2007) Instruments for Assessment of Integration and Academic Satisfaction: Validity Study. Revista Galego-Portuguesa de Psicoloxía e Educación 14(1): 12-18.

4. Santos A, Polydoro S, Scortegagna S, Linden M (2013) Integration to Higher Education and Academic Satisfaction in University Students. Psychology: science and profession 33(4): 80-793.

5. Soares A, Mourão L, Mello T (2011) Study for the construction of an instrument of academic-social behavior for university students. Studys and Research in Psychology 11(2): 488-506.

6. Nauta MM (2007) Assessing College Students' Satisfaction with their Academic Majors. Journal of Career Assessment 15(4): 446-462.

7. Soares AP, Almeida LS (2011) Academic Satisfaction Questionnaire. In: Machado C, Simões MR (Eds.), Instruments and Contextsof Psychological Evaluation, Coimbra: Almedina, pp: 103-124.

8. Zhou M, Lin W (2016) Adaptability and Life Satisfaction: The Moderating Role of Social Support. Front Psychol 7: 1134.
9. Bardagi M, Hutz, C (2012) Academic Routine and Relationship with Colleagues and Teachers: Impact on University Evasion. Psico 43(2): 174-184.

10. Soares A, Almeida L, Dinis A, Guisande A (2006) Modelo multidimensional de ajustamento de jovens ao contexto universitário (MMAU): Estudo com estudantes de ciências e tecnologias versus ciências sociais e humanas. Análise Psicológica 24(1): 15-27.

11. Almeida LS, Soares AP (2002) Academic Experience Questionnaire (QVA-r): Evaluation of the adjustment of university students. Psychological Assessment 2: 81-93.

12. Sisto F, Muniz M, Bartholomeu D, Neusa Pasetto P, Oliveira A, et al. (2008) Study for the construction of Academic Satisfaction Scale for University Students. Psychological Evaluation 7(1): 45-55.

13. Villar J, Santos A (2001) University Experience Questionnaire: Adaptation for Brazilian students. Itatiba, SP: São Francisco University.

14. HERI (2017) Overview of Surveys, Higher Education Research Institute.

15. Almeida LS, Soares AP, Ferreira JA (2000) Transition and adaptation to the University: Presentation of the Academic Experience Questionnaire (QVA). Psychology XIX(2): 189-208.

16. Almeida LS, Soares AP, Ferreira JA (2001) Adaptation, income and development of students in Higher Education: Construction of the Academic Experience Questionnaire. Methodus 1:3-20.

17. Almeida L, Soares A, Ferreira J (2002) Academic Experience Questionnaire (QVA-r): Evaluation of the adjustment of university students. Psychological Assessment 2: 81-93.

18. Granado JIF, Santos AAA, Almeida LS, Soares AP, Guisande MA (2005) Academic integration of university students: Contributions for the adaptation and validation of QVA-r in Brazil. Psychology and Education 4: 33-43.

19. Schleich A, Polydoro S, Santos A (2006) Scale of satisfaction with the academic experience of students of higher education. Avaliação Psicológica 5(1): 1120. 